\title{
MAPAS CONCEITUAIS NO ENSINO DE CIÊNCIAS: \\ Uma estratégia potencialmente significativa para o processo \\ didático
}

\author{
Raylen Pereira de Ramos' \\ Viviane Aparecida Bagio²
}

\section{RESUMO}

O mapa conceitual é uma estratégia pedagógica que pode ser utilizada como técnica para ensinar, aprender, pesquisar e avaliar. E, considerando tal potencialidade, o presente estudo de abordagem qualitativa utilizando da pesquisa-ação, objetivou analisar a produção de mapas conceituais antes e após o estudo do sistema digestório, para explicitar a aprendizagem significativa mediada pelas operações de pensamento utilizadas e relações entre os conceitos. Como dados de pesquisa foram analisados os mapas produzidos por quatro alunas do $8^{\circ}$ ano do ensino fundamental, a fim de refletir como evidenciam os conhecimentos prévios e as possíveis aprendizagens. A fundamentação teórica da pesquisa perpassa desde a compreensão sobre a estratégia do mapa conceitual, as operações de pensamento mobilizadas e aprimoradas em sua elaboração, associado ainda à teoria da aprendizagem significativa. Além disso, foi realizada uma pesquisa bibliográfica, com o intuito de perceber como essa estratégia tem sido proposta nos estudos relacionados ao ensino de Ciências nos anos finais do ensino fundamental enquanto instrumento de coleta de dados. A análise dos dados, coletados nos dois momentos da pesquisa, evidencia que o mapa conceitual pode ser compreendido como uma estratégia potencialmente significativa para a aprendizagem. Consideramos que ele possibilitou evidenciar os conhecimentos prévios, desvelar o desenvolvimento das operações de pensamento predominantes nesta técnica e expressar a rede de relações conceituais que as alunas construíram, além de destacar a necessidade de o professor atuar na perspectiva mediadora do processo ensino-aprendizagem.

Palavras-chave: Mapa conceitual. Aprendizagem significativa. Ensino de Ciências.

\footnotetext{
1 Mestranda em Biologia Evolutiva no Programa de Pós-Graduação em Biologia Evolutiva pela associação entre a Universidade Estadual de Ponta Grossa (UEPG) e a Universidade Estadual do Centro-Oeste (Unicentro). Licenciada em Ciências Biológicas pela Universidade Estadual de Ponta Grossa (UEPG). Orcid iD: https://orcid.org/0000-0002-3867-3521. E-mail: raylenram@gmail.com

2 Doutora em Educação pela UEPG. Mestra em Educação em Ciências e em Matemática. Licenciada em Pedagogia e em Matemática. Professora colaboradora da área de Didática do Departamento de Pedagogia da Universidade Estadual de Ponta Grossa. Orcid iD: https://orcid.org/0000-0003-0001-1546. E-mail: vivibagio@gmail.com
} 


\title{
CONCEPTUAL MAPS IN SCIENCE TEACHING:
}

\section{A potentially significant strategy for the didactic process}

\begin{abstract}
The conceptual map is a pedagogical strategy that teachers use as a technique to teaching, learning, researching, and evaluation. Moreover, considering such potentiality, the present study of qualitative approach using research-action, aimed to analyze the production of conceptual maps before and after the study of the digestive system to explain the significant learning mediated by the operations of thought used and relationships between the concepts. As research data, students from 8th year of elementary school produced maps and they were analyzed to reflect how they demonstrate previous knowledge and possible learning. The theoretical basis of the research goes from the understanding about the strategy of the conceptual map, the thought operations mobilized and improved in its elaboration, also associated to the theory of significant learning. In addition, a bibliographical research was carried out in order to understand how this strategy has been proposed in studies related to science teaching in the final years of elementary school as an instrument of data collection. The analysis of the data collected in both moments of the research shows that it is possible to understand the map as a potentially significant strategy for learning. We consider that it has made it possible to highlight the previous knowledge, reveal the development of the thinking operations predominant in this technique, and express the network of conceptual relationships that the students have built, in addition to highlighting the need for the teacher to act in the mediating perspective of the teaching-learning process.
\end{abstract}

Keywords: Conceptual map. Meaningful learning. Science teaching.

\section{MAPAS CONCEPTUALES EN LA ENSEÑANZA DE CIENCIAS: Una estrategia potencialmente significativa para el proceso didáctico.}

\section{RESUMEN}

El mapa conceptual es una estrategia pedagógica que se puede utilizar como técnica para enseñar, aprender, investigar y evaluar. $Y$, considerando esta potencialidad, el presente estudio con enfoque cualitativo utilizando la investigación-acción, tuvo como objetivo analizar la producción de mapas conceptuales antes y después del estudio del aparato digestivo, para explicar el aprendizaje significativo mediado por las operaciones de pensamiento utilizadas y las relaciones entre los conceptos. Como datos de la investigación, se analizaron los mapas que fueron elaborados por cuatro alumnos de $8^{\circ}$ año de primaria para reflejar cómo demuestran conocimientos previos y posibles aprendizajes. La base teórica de la investigación pasa por comprender la estrategia del mapa conceptual, las operaciones del pensamiento movilizadas y mejoradas en su elaboración, asociadas a la teoría del aprendizaje significativo. Además, se realizó una búsqueda bibliográfica con el fin de comprender cómo esta estrategia se ha propuesto en estudios relacionados con la enseñanza de las ciencias en los últimos años de la educación básica como instrumento de recolección de datos. El análisis 
de los datos, recogidos en los dos momentos de la investigación, muestra que el mapa conceptual puede entenderse como una estrategia potencialmente significativa para el aprendizaje. Creemos que permitió resaltar conocimientos previos, develar el desarrollo de las operaciones del pensamiento prevalecientes en esta técnica y expresar el entramado de relaciones conceptuales que construyeron los estudiantes, además de resaltar la necesidad de que el docente actúe en la perspectiva mediadora del proceso de enseñanza-aprendizaje.

Palabras clave: Mapa conceptual. Aprendizaje significativo. Enseñanza de las ciencias.

\section{INTRODUÇÃO}

Todo professor, ao debruçar-se no momento do planejamento e, posteriormente, na ação de ensinar, considera que seu trabalho tem como finalidade a aprendizagem, independentemente da abordagem de ensino que ele utilize. A aprendizagem pode ocorrer, por exemplo, de modo mecânico, repetitivo, interativo ou associativo. Alguns professores, quando questionados sobre o tipo de aprendizagem ao qual direcionam seu trabalho, afirmam almejar uma aprendizagem significativa.

Para compreender o que é e algumas relações sobre a teoria da aprendizagem significativa, utilizamos como estratégia pedagógica o mapa conceitual no ensino de Ciências. Ele pode ser tanto uma técnica de ensino, como de avaliação e um modo de expressar a aprendizagem e suas implicações.

A temática investigada foi o "sistema digestório", objeto de ensino-aprendizagem de quatro alunas matriculadas no $8^{\circ}$ ano de uma escola particular, em que o mapa conceitual foi utilizado a priori e a posteriori de uma sequência didática sobre esse conteúdo. A questão que orientou a pesquisa foi: Como o mapa conceitual pode expressar as aprendizagens sobre o sistema digestório? O objetivo do estudo foi o de analisar a produção de mapas conceituais antes e após a sequência didática para explicitar a aprendizagem significativa mediada pelas operações de pensamento utilizadas e relações entre os conceitos.

Como metodologia de pesquisa adotou-se a pesquisa-ação, fundamentada na natureza qualitativa, com aporte em Thiollent (1996). A fundamentação teórica adotada explicita o uso de mapas conceituais no 
ensino de Ciências nos anos finais do ensino fundamental, além das compreensões a respeito dessa estratégia e da teoria da aprendizagem significativa. Segundo Veiga (2013), com o mapa conceitual transforma-se o abstrato em concreto, favorece articulações entre teoria e prática, além de possibilitar a construção de relações significativas.

Os mapas conceituais podem ter muitas funções, diferentes encaminhamentos, diferentes perspectivas e vários modos de compreensão. Devido a isso, o objetivo desse trabalho é refletir como eles evidenciam, tanto os conhecimentos prévios como as possíveis aprendizagens que são emergentes do seu uso.

Tal delineamento conceitual visa a compreender como as pesquisas investigam o uso de mapas conceituais, bem como a confrontá-los com a possibilidade de serem compreendidos como uma estratégia potencialmente significativa no ensino de Ciências.

\section{REFERENCIAL TEÓRICO}

\section{Os Mapas Conceituais no Ensino de Ciências}

Inicialmente, nos dispusemos a investigar as principais conclusões que as pesquisas que analisaram mapas conceituais no ensino de Ciências destacam. Para tal, foi realizado um estudo bibliográfico, na primeira quinzena de abril de 2020, em três portais com dois grupos descritores. Os portais descritores utilizados e quantitativo de estudos estão no Quadro 1:

Quadro 1 - Portais e descritores utilizados

\begin{tabular}{|} 
Portais e descritores utilizados \\
\hline Portal de periódicos CAPES \\
"mapa conceitual" AND "ciências" AND "ensino fundamental" = 22 resultados \\
"mapas conceituais" AND "ciências" AND "ensino fundamental" = 33 resultados \\
BDTD - Biblioteca Digital Brasileira de Teses e Dissertações \\
"mapa conceitual" AND "ciências" AND "ensino fundamental" = 13 resultados \\
"mapas conceituais" AND "ciências" AND "ensino fundamental" $=30$ resultados \\
Portal de Teses e Dissertações - CAPES \\
"mapa conceitual" AND "ciências" AND "ensino fundamental" = 30 resultados \\
\hline "mapas conceituais" AND "ciências" AND "ensino fundamental" = 67 resultados \\
Total = 195 publicações
\end{tabular}

Fonte: Elaborado pelas autoras, 2020. 
Foram definidos os seguintes critérios de exclusão: estudos indisponíveis na plataforma, duplicatas, trabalhos apresentados em eventos e publicações sem autorização de divulgação. Como critério de inclusão para a seleção dos estudos foram selecionados os trabalhos que abordassem temáticas de ciências, que tratassem de pesquisas realizadas com alunos do ensino fundamental $\left(6^{\circ}\right.$ ao $9^{\circ}$ ano) e que utilizassem a ferramenta mapa conceitual ao longo da pesquisa.

A partir disso, foram analisados 17 trabalhos, porém muitos tinham outra perspectiva de enfoque, como o uso de software em sala de aula. Em alguns trabalhos o mapa não era o objeto direto de estudo, em outros ele não foi analisado, e ainda trabalhos que, apesar de o mapa ser feito no ensino fundamental, o corpo do mapa conceitual não foi produzido pelos alunos. Com isso, restaram seis trabalhos que se encontram no Quadro 2, a seguir:

Quadro 2 - Trabalhos analisados

\begin{tabular}{|c|c|c|}
\hline Estudos & Temática(s) & Nível escolar \\
\hline Magalhães (2015) & Leis de Newton & $9^{\circ}$ Ano \\
\hline Andrade (2016) & Corpo humano & $8^{\circ}$ Ano \\
\hline Salviato (2009) & Aquecimento global & $8^{\circ}$ Ano \\
\hline Lourenço (2008) & Argila & $8^{\circ}$ Ano \\
\hline Oliveira, Henckes e Strohschoen (2019) & Seres vivos & $7^{\circ}$ Ano \\
\hline Weber (2013) & Células & $7^{\circ}$ Ano \\
\hline
\end{tabular}

Fonte: Elaborado pelas autoras, 2020.

Os seis estudos obtidos foram realizados com alunos do $7^{\circ}$ ao $9^{\circ}$ ano do ensino fundamental. Com relação à compreensão sobre o mapa conceitual, $34 \%$ o considerou como uma estratégia de ensino, $50 \%$ uma estratégia de aprendizagem e 50\% um instrumento de avaliação. Tal perspectiva evidencia as múltiplas possibilidades que o trabalho com essa estratégia pedagógica possibilita, bem como as compreensões de ensino, aprendizagem e avaliação associadas, uma vez que em alguns trabalhos há mais de uma concepção.

Em $67 \%$ das pesquisas, a teoria da aprendizagem significativa estava presente. Em Salviato (2009) e Weber (2013), a estratégia pedagógica em 
tela foi utilizada em dois momentos da pesquisa. Entretanto, apenas Salviato (2009) estabeleceu uma análise comparativa, a qual também é objeto do estudo aqui sistematizado. A autora concluiu que foi possível perceber evolução qualitativa e quantitativa sobre as produções:

\begin{abstract}
Os mapas conceituais a posteriori de todos os estudantes da amostra apresentaram aumento na quantidade de conceitos e proposições, demonstrando a inserção de novos conhecimentos em sua rede conceitual. As relações estruturais, organizacionais e hierárquicas destes conceitos puderam ser observadas com base na comparação dos mapas a priori e a posteriori e demonstraram relevantes reorganizações cognitivas em todos os mapas a posteriori dos estudantes (SALVIATO, 2009, p. 95).
\end{abstract}

Todos os estudos analisados inferem as contribuições dessa estratégia pedagógica, tanto para o processo de ensino quanto de aprendizagem e inclusive de avaliação. Apenas o estudo de Magalhães (2015) não afirmou que o mapa possibilita a aprendizagem significativa devido à ausência de ligações entre os conceitos, porém relata a construção do conhecimento pelos alunos.

Na sequência discorremos a respeito da aprendizagem significativa, uma das teorias que destaca o desenvolvimento processual, com 0 aprimoramento dos subsunçores e, na qual, por exemplo, o mapa conceitual evidencia a rede de relações entre os conhecimentos adquiridos e os conhecimentos prévios.

\title{
Aprendizagem Significativa e Materiais Potencialmente Significativos
}

A aprendizagem significativa, conforme Moreira (2013, p. 43), "é uma teoria cognitivista construtivista que se ocupa da cognição, com significado, em situação formal de ensino". Esse viés teórico teve sua origem em 1963 com David Ausubel, recebendo posteriormente contribuições de vários pesquisadores como, Joseph Novak, Bob Gowin e Marco Antonio Moreira (BORSSOI; ALMEIDA, 2013).

Segundo Moreira (2012, p. 2), a aprendizagem significativa "é aquela em que ideias expressas simbolicamente interagem de maneira substantiva e 
não arbitrária com aquilo que o aprendiz já sabe (subsunçor)". O subsunçor refere-se ao conhecimento já existente na estrutura cognitiva do indivíduo, o qual é dinâmico e pode evoluir. O autor destaca ainda que: "Subsunçores podem ser proposições, modelos mentais, construtos pessoais, concepções, ideias, invariantes operatórios, representações sociais e, é claro, conceitos, já existentes na estrutura cognitiva de quem aprende" (MOREIRA 2012, p. 10).

Quando 0 aprendiz consegue fazer conexões entre $\bigcirc$ que está aprendendo e o seu conhecimento prévio, ele constrói significados pessoais para essa informação e a transforma em conhecimentos. Dessa forma, é desenvolvida a capacidade de utilizar esse conhecimento em contextos diferentes. A aprendizagem significativa é a interação entre aquilo que já se sabe e um novo conhecimento em que ambos se articulam e modificam (MOREIRA, 1998).

Para que ocorra a aprendizagem significativa, Moreira (2012) afirma que algumas condições são necessárias, como, a utilização de materiais potencialmente significativos e a predisposição do aluno para aprender. Segundo o mesmo autor, "um material será potencialmente significativo se estiver bem organizado, estruturado, aprendível, e se o aprendiz tiver conhecimentos prévios que lhe permitam dar significados aos conteúdos veiculados por esse material" (MOREIRA, 2013, p. 4).

Para analisar as possíveis aprendizagens significativas sobre 0 conteúdo "sistema digestório" na aula de Ciências do $8^{\circ}$ ano do ensino fundamental, escolhemos a estratégia pedagógica do mapa conceitual, em que os estudos de Moreira (2013) já afirmam como potencialmente significativo.

\section{Mapa Conceitual}

Os mapas conceituais, além de uma técnica de ensino, são ferramentas gráficas utilizadas para organizar e representar o conhecimento. Neles estão inclusos conceitos que se relacionam, os quais são associados por linhas que os interligam. Nessas linhas podem existir palavras ou frases de ligação especificando a relação entre os conceitos (NOVAK; CAÑAS, 2010). 
Além das linhas entre dois conceitos, pode haver ligações cruzadas, ou seja, relações entre conceitos nos diferentes segmentos ou domínios do mapa conceitual. É importante destacar que as relações cruzadas apontam para uma aprendizagem significativa, na qual o aluno passa a perceber semelhanças e diferenças entre os conhecimentos e os reorganiza de modo que este conhecimento abrange outros conhecimentos (MOREIRA, 2012, 2013). Segundo Mendonça, Silveira e Moreira (2011), as ligações cruzadas evidenciam uma maior compreensão a respeito do tema abordado.

Moreira (1998) sugere que os conceitos dentro do mapa conceitual sejam representados de maneira hierárquica, sendo que os conceitos mais inclusivos/gerais devem estar mais próximos do conceito central/gerador e os mais específicos/menos gerais mais distantes. O autor enfatiza que 0 mapa conceitual deve estar claro quanto aos conceitos mais importantes e aos mais específicos.

Nesse contexto, Moreira (1998, p. 2) declara que: "O importante é que o mapa seja um instrumento capaz de evidenciar significados atribuídos a conceitos e relações entre conceitos no contexto de um corpo de conhecimentos". Ou seja, se ocorrer a união de dois conceitos através de uma linha em um mapa conceitual, o indivíduo deve ser capaz de explicála.

Os mapas conceituais também são descritos por diferentes autores do campo da Didática e das metodologias ativas como uma estratégia pedagógica, a qual pode ser realizada tanto coletiva como individualmente. Anastasiou e Alves (2005, p. 83) apresentam a seguinte proposição sobre o que é, como propor e avaliar mapas conceituais:

Quadro 3 - Descrição sobre como utilizar o mapa conceitual em sala de aula

\begin{tabular}{|c|l|}
\hline DESCRIÇÃO & $\begin{array}{l}\text { Consiste na construção de um diagrama que indica a relação de } \\
\text { conceitos em uma perspectiva bidimensional, procurando mostrar as } \\
\text { relações hierárquicas entre os conceitos pertinentes à estrutura do } \\
\text { conteúdo. }\end{array}$ \\
\hline $\begin{array}{c}\text { OPERAÇÕES DE } \\
\text { PENSAMENTO } \\
\text { (Predominantes) }\end{array}$ & Interpretação/Classificação/Crítica/Organização de dados/Resumo \\
\hline $\begin{array}{c}\text { DINÂMICA DA } \\
\text { ATIVIDADE }\end{array}$ & $\begin{array}{l}\text { O professor poderá selecionar um conjunto de textos, ou de dados, } \\
\text { objetos, informações sobre um tema ou objeto de estudo de uma }\end{array}$ \\
\hline
\end{tabular}




\begin{tabular}{|c|c|}
\hline & $\begin{array}{l}\text { Unidade de ensino e aplicar a estratégia do mapa conceitual propondo } \\
\text { ao estudante a ação de: } \\
\text { - identificar os conceitos-chave do objeto ou texto estudado; } \\
\text { - } \quad \text { selecionar os conceitos por ordem de importância; } \\
\text { - Incluir conceitos e ideias mais específicas; } \\
\text { - Estabelecer relação entre os conceitos por meio de linhas e } \\
\text { identificá-las com uma ou mais palavras que explicitem essa } \\
\text { relação; } \\
\text { - Identificar conceitos e palavras que devem ter um significado ou } \\
\text { - } \quad \text { Buspressam uma proposição; } \\
\text { - Perceber que há várias formas de traçar o mapa conceitual; } \\
\text { - Compartilhar os mapas coletivamente, comparando-os e } \\
\text { - Jumplementando-os; } \\
\text { - Justificar a localização de certos conceitos, verbalizando seu } \\
\text { entendimento. }\end{array}$ \\
\hline AVALIAÇÃO & $\begin{array}{l}\text { Acompanhamento da construção do mapa conceitual a partir da } \\
\text { definição coletiva dos critérios de avaliação: } \\
\text { - Conceitos claros; } \\
\text { - Relação justificada; } \\
\text { - Riqueza de ideias; } \\
\text { - Criatividade na organização; } \\
\text { - Representatividade do conteúdo trabalhado. }\end{array}$ \\
\hline
\end{tabular}

Fonte: Anastasiou e Alves (2005, p. 83).

O exposto pelas autoras na descrição e dinâmica da atividade vai ao encontro do que Moreira (2013) compreende sobre essa estratégia. Depresbiteris e Tavares (2009) também analisam a possibilidade de serem tanto uma estratégia de ensino como um instrumento de avaliação, na medida em que permitem o acompanhamento da aprendizagem, feedback, retomada de conceitos com a explicação das relações construídas. Nesse contexto, a avaliação poderá ser diagnóstica, a fim de identificar os conhecimentos prévios dos alunos, como ressaltam Catani e Galego (2009) e ainda para traçar novos caminhos na aprendizagem (LUCKESI, 201 la). Para Luckesi (2011b) e Nadal e Leão (2002), a avaliação também pode ser formativa, com o intuito de acompanhar o processo de ensino-aprendizagem, intervindo nesse quando necessário, reforçando o processo e qualificando a aprendizagem a partir do feedback ou das possíveis dificuldades decorrentes.

Veiga (2013) também aborda o ensino com mapas conceituais e relata que o processo didático envolve as seguintes dimensões: ensinar, aprender, pesquisar e avaliar. Segundo a autora, os mapas conceituais, 
além de uma estratégia de ensino e promotora de aprendizagem, valorizam a dimensão da pesquisa como um processo criativo para representar o conhecimento. Na avaliação, eles são capazes de evidenciar as particularidades da aprendizagem de cada aluno e possibilitar a autoavaliação por ele ao refletir sobre os conceitos e relações estabelecidas. Souza e Boruchovitch (2010) ainda relatam que os mapas conceituais são importantes para evidenciar uma aprendizagem significativa devido aos constantes processos que ocorrem na estrutura cognitiva e não por estarem certos.

A estratégia descrita a partir de Anastasiou e Alves (2005) detalha que - mapa conceitual mobiliza no estudante $O$ desenvolvimento e aprimoramento de algumas "operações de pensamento". Segundo Raths et al. (1977), elas dizem respeito às diferentes técnicas para estimular a aprendizagem. Essas devem contemplar diferentes ações mentais, mobilizadas pelas estratégias de ensino, de modo que elas devem ser diversificadas para não potencializar apenas alguns tipos de operações de pensamento.

Desse modo, as operações de pensamento precisam ser exercitadas, construídas e despertadas, pois "pensar é uma forma de aprender. Pensar é uma forma de perguntar pelos fatos e, se o pensamento tem algum objetivo, os fatos assim encontrados serão significativos para esse objetivo" (RATHS et al., 1977, p. 15, grifo do autor). As operações de pensamento desenvolvidas na elaboração de um mapa conceitual estão descritas, no Quadro 4, a seguir:

Quadro 4 - Síntese das operações de pensamento exercitadas na elaboração do mapa conceitual

\begin{tabular}{|c|l|}
\hline $\begin{array}{c}\text { OPERAÇÃO DE } \\
\text { PENSAMENTO }\end{array}$ & \multicolumn{1}{|c|}{ CONCEITO/RELAÇÕES } \\
\hline Resumo & $\begin{array}{l}\text { Apresentar de forma condensada a substância do que foi apreciado. } \\
\text { Pode ser combinado com a comparação. }\end{array}$ \\
\hline Classificação & $\begin{array}{l}\text { Colocar em grupos, conforme princípios, dando ordem à existência. } \\
\text { Exige análise e síntese, por conclusões próprias. }\end{array}$ \\
\hline Interpretação & $\begin{array}{l}\text { Processo de atribuir ou negar sentido à experiência, exigindo } \\
\text { argumentação para defender o ponto proposto. Exige respeito aos } \\
\text { dados e atribuição de importância, causalidade, validade e } \\
\text { representatividade. Pode levar a uma descrição inicial para depois }\end{array}$ \\
\hline
\end{tabular}




\begin{tabular}{|c|l|}
\hline Crítica & haver uma interpretação do significado percebido. \\
\hline & $\begin{array}{l}\text { Efetivar julgamento, análise e avaliação, realizando o exame crítico } \\
\text { das qualidades, defeitos, limitações. Segue referência, um padrão ou } \\
\text { critério. }\end{array}$ \\
\hline $\begin{array}{l}\text { Obter e organizar dados é a base de um trabalho independente; } \\
\text { exige objetivos claros, análise de pistas, plano de ação, definição de } \\
\text { dados de } \\
\text { tarefas-chave, definição e seleção de respostas e de tratamento } \\
\text { delas, organização e apresentação do material coletado. Requer } \\
\text { identificação, comparação, análise, síntese, resumo, observação, } \\
\text { classificação, interpretação, crítica, suposições, imaginação, entre } \\
\text { outros. }\end{array}$ \\
\hline
\end{tabular}

Fonte: Adaptado de Anastasiou e Alves (2005, p. 28).

Segundo Veiga (2013), o que torna os mapas conceituais uma ferramenta interessante nas quatro dimensões do processo didático é a sua tipologia, ou seja, sua representação gráfica. Autores como Forte (2007), Arellano e Santoyo (2009) e Tavares (2007), propõem alguns dos modelos possíveis de mapas conceituais destacados no quadro a seguir:

Quadro 5 - Tipologias dos mapas conceituais

\begin{tabular}{|l|l|l|}
\hline Modelo & Descrição & Representação gráfica \\
\hline $\begin{array}{l}\text { Linear } \\
\text { (FORTE, 2007) }\end{array}$ & $\begin{array}{l}\text { Os conceitos estão ligados } \\
\text { com o anterior e o posterior. }\end{array}$ \\
\hline $\begin{array}{l}\text { Leque } \\
\text { (ARELLANO; } \\
\text { SANTOYO, 2009) }\end{array}$ & $\begin{array}{l}\text { Nele incluem relações cíclicas } \\
\text { a), estrutura hierárquica (b e hierárquica com liga } \\
\text { cruzada (d). }\end{array}$ \\
\hline $\begin{array}{l}\text { Teia de Aranha } \\
\text { (TAVARES, 2007) }\end{array}$ & $\begin{array}{l}\text { encontra no meio e a partir } \\
\text { dele criam-se as relações } \\
\text { conceituais. }\end{array}$ \\
\hline $\begin{array}{l}\text { Rede conceitual } \\
\text { (FORTE, 2007) }\end{array}$ & $\begin{array}{l}\text { De qualquer conceito saem } \\
\text { outros conces que ligam com } \\
\text { natural. }\end{array}$ \\
\hline
\end{tabular}

Fonte: elaborado a partir de Arellano e Santoyo (2009), Tavares (2007) e Forte (2007).

As diferentes tipologias deste quadro serão examinadas nos mapas conceituais sobre o sistema digestório, analisados posteriormente, bem como as operações descritas em Anastasiou e Alves (2005) com apoio nos escritos 
de Raths et al. (1977), a fim de observar como essa estratégia de ensino é potencialmente significativa.

\section{PROCEDIMENTOS METODOLÓGICOS}

A pesquisa empreendida de natureza qualitativa, utilizando da abordagem da pesquisa-ação. O estudo foi aprovado pelo Comitê de Ética da Universidade Estadual de Ponta Grossa-UEPG (parecer CAAE 99136918.3.0000.0105). Anterior à coleta dos dados foram entregues termos de autorização à direção da escola, bem como, aos pais e responsáveis o termo de consentimento livre e esclarecido para a autorização da participação na pesquisa. As quatro alunas participantes do estudo também assinaram um termo de assentimento.

A coleta dos dados ocorreu no mês de novembro de 2018, com quatro alunas regularmente matriculadas no $8^{\circ}$ ano do ensino fundamental de um colégio particular de Ponta Grossa. A fim de não identificar as participantes, as denominamos de $\mathrm{A} 1, \mathrm{~A} 2, \mathrm{~A} 3$ e $\mathrm{A} 4$.

Conforme exposto por Thiollent (1996, p. 14), "a pesquisa-ação associa uma base empírica que é concebida e realizada em estreita associação com uma ação", seguindo quatro fases: exploratória, planejamento, execução e avaliação. A primeira foi consolidada com a elaboração dos mapas conceituais iniciais $(\mathrm{MCl})$, seguida do planejamento de uma sequência didática. A fase de execução foi a aplicação de uma oficina organizada como sequência didática com duração de três horas/aula, utilizando de diferentes recursos e modelos do sistema digestório, todos confeccionados com materiais alternativos. A última etapa foi efetivada com a elaboração de um novo mapa conceitual (denominado de mapa conceitual final-MCF), ao final da oficina, sem acesso a nenhum material.

Os dois mapas permitiram um comparativo entre os conceitos e relações expressos nos dois momentos. O número de participantes foi definido pelo interesse em participar da oficina, realizada em contraturno. 


\section{APRESENTAÇÃO E DISCUSSÃO DOS RESULTADOS}

Os mapas conceituais foram analisados segundo as compressões de Anastasiou e Alves (2005) e Raths et al. (1977). O estudo dos mapas conceituais iniciais evidenciou que foram utilizadas predominantemente as operações de pensamento: resumo, classificação e organização e obtenção dos dados.

Com relação à operação resumo, três mapas conceituais apresentaram perdas de aspectos importantes na concisão de ideias. Essa afirmação advém, por exemplo, da descrição não sequencial dos órgãos do caminho da digestão com as principais funções, juntamente com a baixa quantidade de relações entre os conceitos relativos ao conhecimento prévio sobre o sistema digestório. Na Figura 1, exemplificamos $\circ \mathrm{MCl}$ elaborado pela participante A3:

Figura 1 - Mapa conceitual inicial elaborado pela participante A3

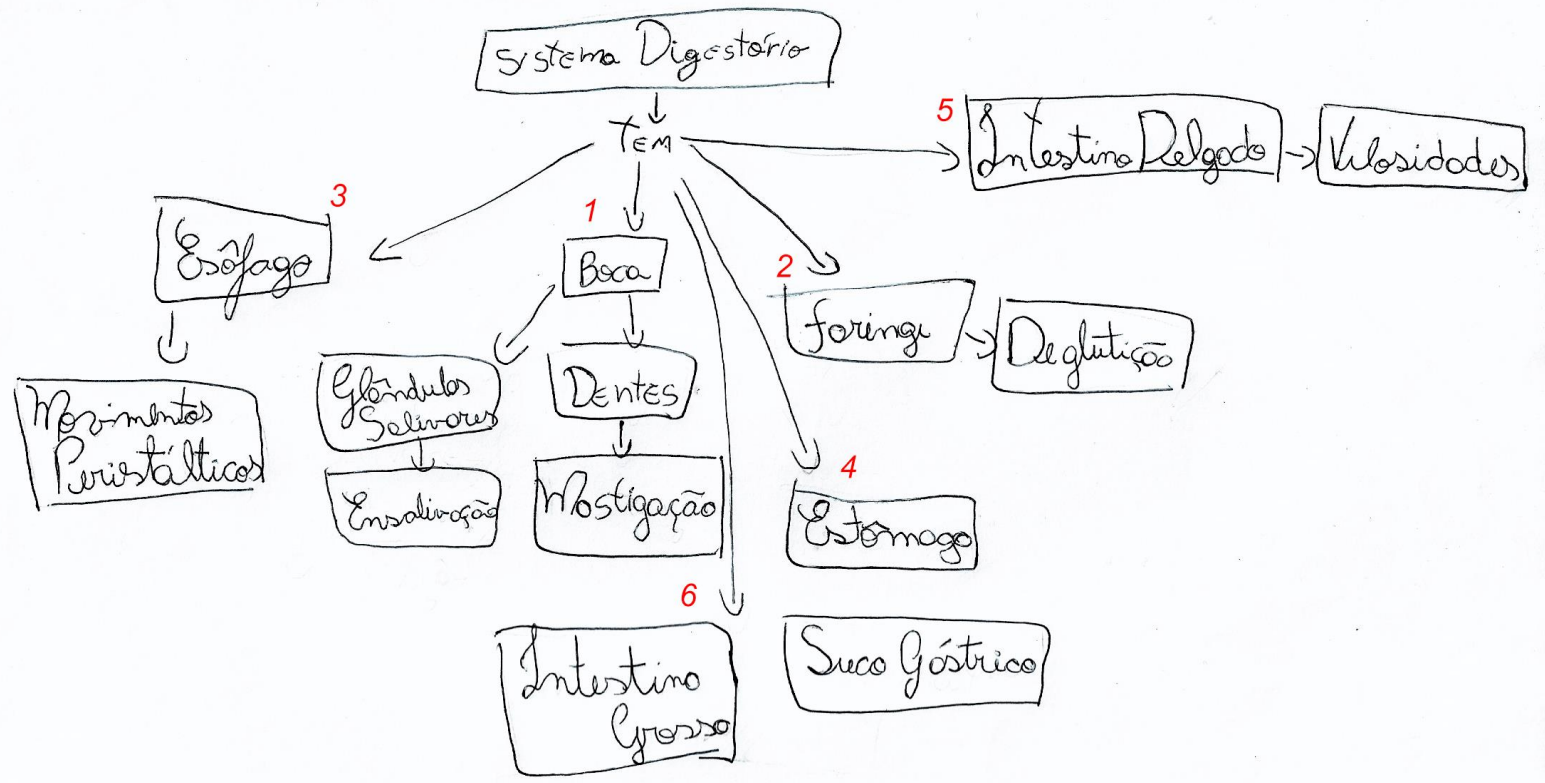

Fonte: Dados de pesquisa.

Legenda: Os números de 1 a 6 indicam a classificação em grupos feita pela aluna, bem como a ordem do caminho da digestão, que evidencia a dificuldade da aluna em estabelecer ordem de hierarquia entre os órgãos, bem como a dificuldade em organizar os dados que ela já sabia acerca do sistema digestório. 
Com relação à classificação, em todos os mapas iniciais, as participantes separaram em grupos cada órgão abordado e os números (nas Figuras 1 e 2) indicam esses grupos, como também o caminho da digestão. Alguns mapas evidenciam as relações cruzadas entre as funções dos órgãos e foram marcadas na imagem dos mapas com o alfinete verde (ANASTASIOU; ALVES, 2005; MENDONÇA; SILVEIRA; MOREIRA, 2011).

Dois dos quatro mapas não apresentaram clareza de classificação e importância relacionada aos conceitos. Exemplo disso está na Figura 1 (acima), pois A3 não apresenta uma ordem quanto ao caminho da digestão, não estabelecendo relação de hierarquia entre os órgãos (vide números em vermelho que indicam o real caminho da digestão). Os mapas de A2 e A3 apresentaram a enumeração de ideias mais importantes, colocando os órgãos seguidos de sua função de forma hierárquica, como é observado na Figura 2, na qual é possível observar a relação hierárquica entre os órgãos e dos órgãos com a sua função (vide números em vermelho).

Figura 2 - Mapa conceitual inicial elaborado pela participante A2

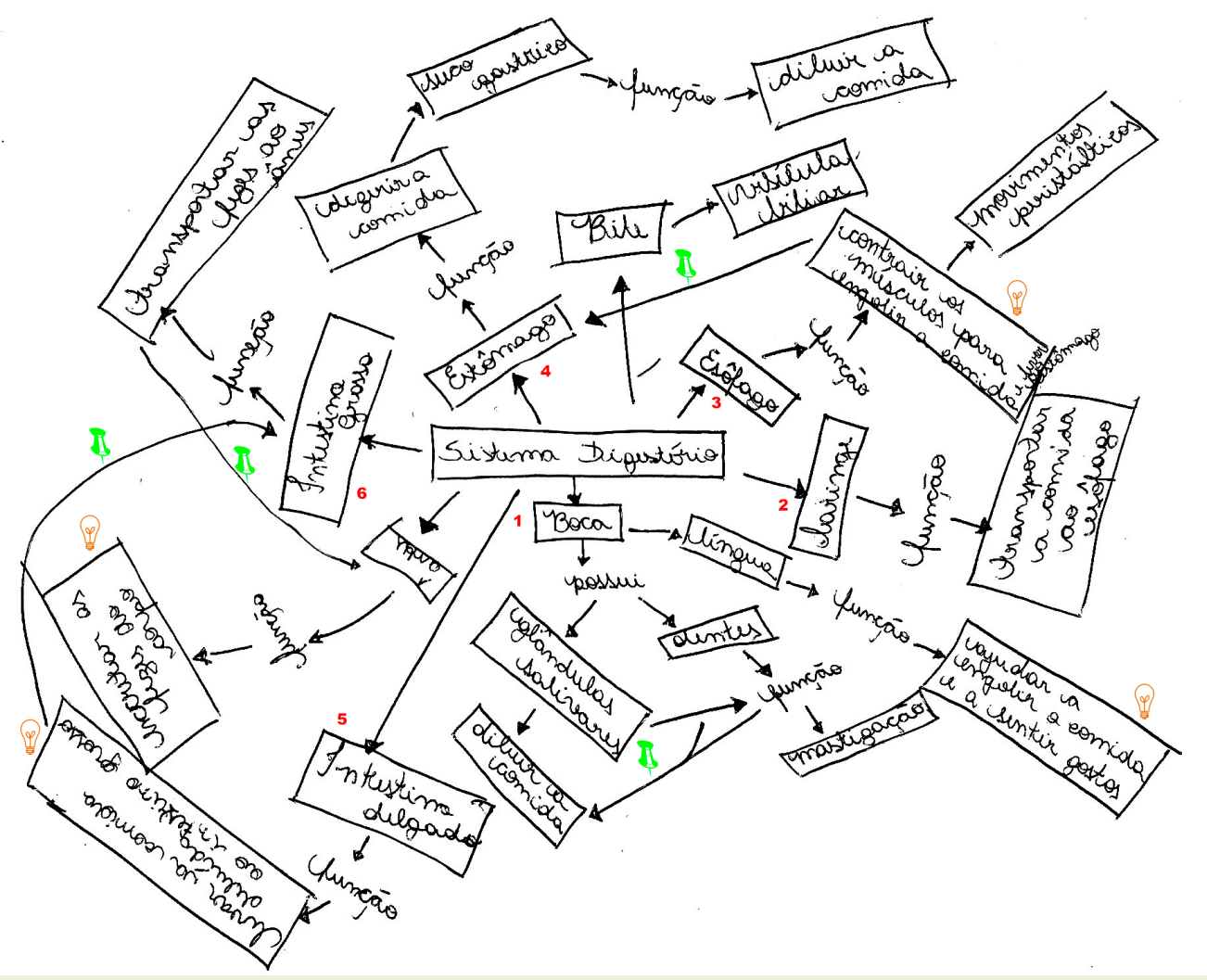


Fonte: Dados de pesquisa.

Legenda: Os alfinetes verdes indicam as relações cruzadas estabelecidas pela aluna entre as funções de diferentes órgãos. Os números vermelhos indicam a relação hierárquica que a aluna estabeleceu entre os órgãos, bem como a classificação em grupos de cada órgão e sua respectiva função. As lâmpadas estão representando a operação de Crítica e Interpretação, na qual a aluna explicou os conceitos postos no mapa.

A respeito da operação obtenção e organização dos dados, todos os mapas a apresentaram, porém alguns com visível dificuldade na organização, por exemplo, na Figura 1 a aluna colocou órgãos sem relação com o caminho da digestão ao lado um do outro, como a boca ao lado do intestino grosso.

Além disso, os mapas apresentaram conceitos errados, como a diluição da comida pelo suco gástrico na Figura 2, o que evidencia uma compreensão equivocada (ou não expressa adequadamente) do conceito. Apenas o mapa conceitual inicial da participante A2 apresentou a operação Interpretação, colocando exemplos a respeito da função do órgão, que estão marcados com a lâmpada na Figura 2.

Ademais das compreensões de Anastasiou e Alves (2005) e de Raths et al. (1977), analisamos os mapas conceituais a partir de sua forma estrutural, descrita por Forte (2007), Arellano e Santoyo (2009) e Tavares (2007), e ainda utilizando o quadro de agrupamentos de preposições para análise de mapas conceituais proposto por Mendonça, Silveira e Moreira (2011), a partir das relações estabelecidas nos mapas, conforme expressa o Quadro 6: 
Quadro 6 - Categorias de agrupamentos adotados nas análises dos mapas conceituais (MC)

\begin{tabular}{|c|c|c|}
\hline Categorias & Características & Informações relevantes \\
\hline $\begin{array}{l}\text { MC Bom (MB): } \\
\text { indica maior } \\
\text { compreensão do } \\
\text { tema. }\end{array}$ & $\begin{array}{l}\text { Contém informações } \\
\text { conceituais relevantes, está } \\
\text { bem hierarquizado com o } \\
\text { conceito inclusor no topo, em } \\
\text { seguida os intermediários e } \\
\text { posteriormente os mais } \\
\text { específicos. }\end{array}$ & $\begin{array}{l}\text { Palavras de ligação adequadas; } \\
\text { com ligações cruzadas; ausência } \\
\text { de repetição de conceitos e } \\
\text { informações } \\
\text { proposições corretas. }\end{array}$ \\
\hline $\begin{array}{l}\text { MC Regular (MR): } \\
\text { indica pouca } \\
\text { compreensão do } \\
\text { tema. }\end{array}$ & $\begin{array}{l}\text { Apresenta (alguns) conceitos } \\
\text { centrais do tema, mas, ainda } \\
\text { assim, com uma hierarquia } \\
\text { apreciável. }\end{array}$ & $\begin{array}{l}\text { As palavras de ligação e os } \\
\text { conceitos não estão claros. Realiza } \\
\text { ligações cruzadas ou não. Muitas } \\
\text { informações detalhistas e a } \\
\text { repetição de conceitos. }\end{array}$ \\
\hline $\begin{array}{lr}\text { MC } & \text { Deficiente } \\
\text { (MD): } & \text { indica } \\
\text { ausência r de } \\
\text { compreensão do } \\
\text { tema. }\end{array}$ & $\begin{array}{l}\text { Não apresenta os conceitos } \\
\text { centrais do tema, muito pobre } \\
\text { em conceitos sobre o conteúdo } \\
\text { trabalhado. }\end{array}$ & $\begin{array}{l}\text { Hierarquia básica, demonstrando } \\
\text { sequências lineares } \\
\text { conhecimentos muito simples. } \\
\text { Faltam relações cruzadas, com } \\
\text { palavras de ligação; são muito } \\
\text { simples. }\end{array}$ \\
\hline
\end{tabular}

Fonte: Mendonça, Silveira e Moreira (2011, p. 101).

Com base nas categorias de Mendonça, Silveira e Moreira (2011), julgamos que três mapas iniciais foram considerados deficientes, indicando pouco conhecimento prévio acerca do tema (como exemplificado na Figura 1) e um foi considerado bom, revelando que a aluna A2 possui um maior conhecimento prévio sobre o sistema digestório, como expresso na Figura 2.

Os mesmos critérios de análise foram pontuados nos quatro mapas conceituais finais. Considerando inicialmente as operações de pensamento de Raths et al. (1977), que em todos os mapas evidenciaram o resumo enquanto concisão de ideias, sem perdas de conceitos importantes. Isso demonstra que as alunas conseguiram utilizar adequadamente a estratégia proposta, sendo que três mapas apresentaram enumeração de ideias importantes, abordando os órgãos seguidos de suas funções de maneira hierárquica, como o mapa elaborado por A4, expresso na Figura 3, em que a própria aluna colocou números para indicar o caminho da digestão: 
Figura 3 - Mapa conceitual final elaborado pela participante A4

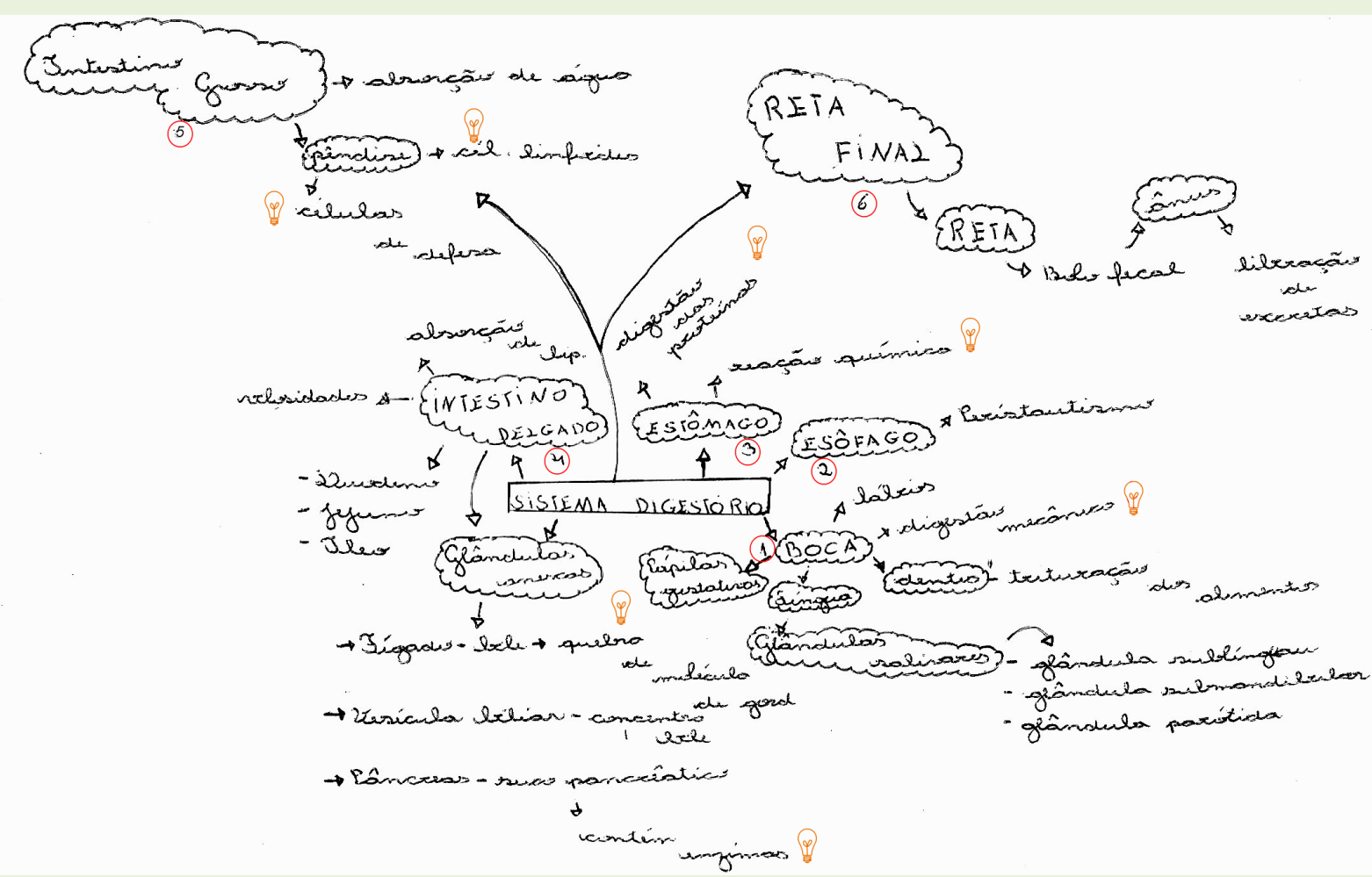

Fonte: Dados da pesquisa.

Legenda: As lâmpadas representam as operações de Crítica e interpretação realizadas pela aluna. Os círculos em vermelho evidenciam a enumeração realizada pela aluna quando estabeleceu a hierarquia entre os órgãos, bem como a classificação em grupos de cada órgão e sua respectiva função.

Quanto à operação classificação, todos os mapas finais identificaram cada órgão e sua respectiva função, e dois mapas apresentaram o caminho da digestão entre os órgãos, como mostra a Figura 3. Isso sugere uma ressignificação de ideias, que vai ao encontro de Anastasiou e Alves (2005), quando as autoras afirmam que a ruptura e continuidade de ideias ocorre com frequência em mapas conceituais.

A respeito da operação interpretação, todos os mapas finais a apresentaram, pois continham exemplos, eram descritos e explicativos. O mesmo ocorreu com a crítica, pois apresentaram provas que foram consideradas como os exemplos a respeito da função do órgão e estão evidenciados com a lâmpada na Figura 3, apresentada anteriormente. Isso demonstra que as alunas ganharam novos conceitos e sugere uma mudança na estrutura cognitiva das alunas (ANASTASIOU; ALVES, 2005). Para 
Veiga (2013), isso o torna importante na promoção de uma aprendizagem significativa. A obtenção e organização dos dados também é uma ação mental que apresentou melhoria significativa, pois as alunas conseguiram demonstrar a relação hierárquica entre os conceitos, como é possível observar tanto no mapa de A4 (Figura 3) como de A2, na Figura 4, abaixo:

Figura 4 - Mapa conceitual final elaborado pela participante A2

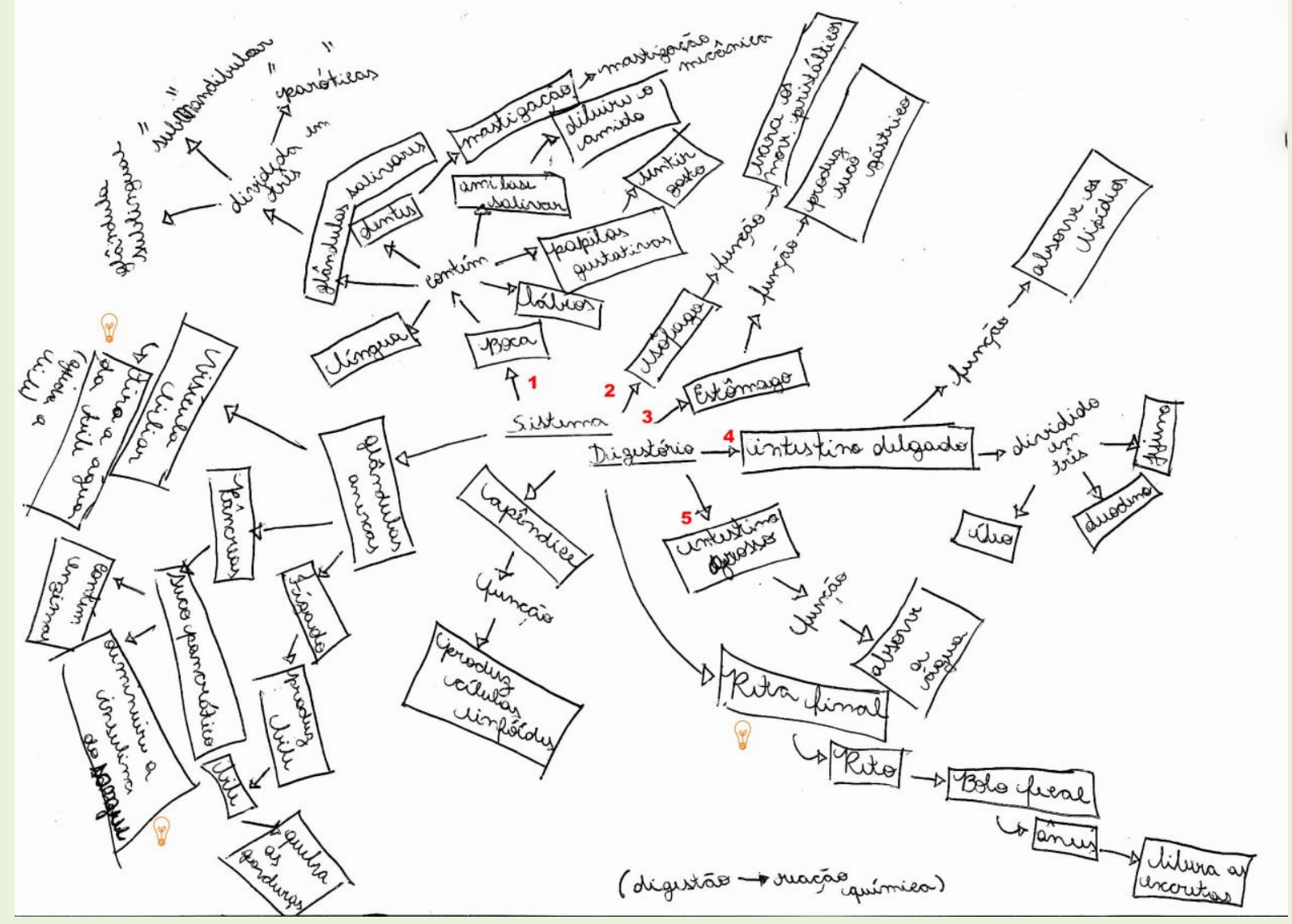

Fonte: Dados da pesquisa.

Legenda: As lâmpadas evidenciam as operações de Crítica e Interpretação. Os números destacam o caminho da digestão no sistema digestório.

Santos e Meira (2015) explicam que o mapa conceitual é considerado uma estratégia de baixa complexidade. Apesar disso, podemos observar que houve um aumento das operações de pensamento utilizadas pelas alunas entre a produção inicial e final, principalmente quanto ao aprimoramento das operações de pensamento relacionadas à crítica e a interpretação. Segundo os autores, todas as operações de pensamento necessitam de operações prévias para serem ancoradas na estrutura 
cognitiva, possivelmente essas prévias para a ancoragem das operações Crítica e Interpretação foram desenvolvidas no decorrer da sequência didática.

Ainda segundo Anastasiou e Alves (2005), a operação Interpretação pode levar a uma descrição inicial dos conceitos para depois haver a interpretação do significado atribuído, e isso ocorre nos mapas iniciais quando as alunas citaram os conceitos e nos finais quando buscaram exemplos para tais conceitos, percebendo o significado atribuído para aquela relação.

Em Anastasiou e Alves (2005), pudemos perceber que a ação mental de organizar e obter dados engloba outras operações (conforme exposto no Quadro 4). De acordo com Santos e Meira (2015), ela exige cerca de 83\% de todas as operações existentes, incluindo outras que não foram analisadas neste estudo, mostrando a complexidade do processo de pensamento. A comparação entre os dois momentos de elaboração dos mapas conceituais evidencia o aprimoramento dessa operação na aprendizagem do sistema digestório, pois em todas as produções finais as alunas analisaram o conhecimento que possuíam, estabeleceram os conceitos centrais e apresentaram as relações entre eles, tornando o modelo conceitual mais rico de preposições.

A partir das categorias de agrupamentos da análise dos mapas conceituais finais expressa por Mendonça, Silveira e Moreira (2011), consideramos que três mapas estão em um nível regular (A1, A3 e A4) exemplificados na Figura 3 - enquanto a aluna A2 manteve-se no nível bom. A alteração do nível dos três mapas, que na elaboração inicial foram classificados como ineficiente, expressa um avanço na aprendizagem do conteúdo proposto. Para a aluna que se manteve na categoria $M B$, comparando as Figuras 1 e 4 observamos tanto $O$ aprimoramento de conceitos quanto a ressignificação de outros e novas relações estabelecidas sobre o sistema digestório.

Com relação à análise estrutural dos Mapas Iniciais, dois mapas apresentaram formato linear, que para Forte (2007), é uma maneira muito 
simples e reduzida de relacionar os conceitos; um mapa apresentou formato de leque, como o da Figura 1, na qual a aluna coloca o sistema digestório como o conceito mais importante e seguido abaixo estão os órgãos que o compõem relacionados de maneira hierárquica. Para Arellano e Santoyo (2009), essas formas de representação do mapa conceitual são as mais simples de descrever a relação entre os conceitos.

O outro mapa apresentou formato de teia de aranha, como o da Figura 2, em que a aluna coloca o sistema digestório como o conceito central, e a partir dele relaciona os órgãos e suas funções, o que segundo Veiga (2013) é uma maneira fácil de estruturar, pois os conceitos partem de um conceito gerador que é o sistema digestório.

Os mapas finais apresentaram os formatos de teia de aranha (Figura 4), leque e rede conceitual. No mapa da Figura 3, em formato de rede, a aluna coloca o sistema digestório como conceito mais importante, pois ele está destacado dos outros conceitos e a partir dele cria várias relações, ressaltando a complexidade do mapa conceitual, pois ela possui um alto nível de conectividade entre os conceitos (VEIGA, 2013).

As diferentes representações gráficas ratificam a variedade de possibilidades de representação do conhecimento que são viabilizadas pelo mapa conceitual, desde as ligações mais simples entre os conceitos às mais complexas e com relações articuladas, pois demonstram que além da modificação na rede de conhecimentos, expressam os significados pessoais e subsunçores já incorporados, bem como indícios da aprendizagem em processo de estabilização (VEIGA, 2013; MOREIRA, 2012).

A fim de analisar a potencialidade de aprendizagem emergente da elaboração dos mapas conceituais, a Tabela 1 expressa quantitativamente algumas proposições comparativas entre eles:

Tabela 1 - Tabela de proposições dos Mapas conceituais Iniciais e Finais

ASPECTOS EXAMINADOS

TOTAL DE RELAÇÕES

PREPOSIÇÕES VÁLIDAS
MAPAS INICIAIS

$63(100 \%)$

$13(20,64 \%)$
MAPAS FINAIS

136 (100\%)

$9(6,6 \%)$ 


\section{\begin{tabular}{llll|l} 
AUSÊNCIA DE RELAÇÕES ENTRE OS & 50 (79,36\%)
\end{tabular} CONCEITOS}

$127(93,4 \%)$

Fonte: Adaptado de Souza, Pinheiro e Miquelin (2018).

Legenda: O total de relações foi a soma das relações encontradas no mapa, tanto no inicial como no final.

As preposições válidas são as denominações para as palavras de ligação entre dois ou mais conceitos (NOVAK; CAÑAS, 2010). Observamos que, considerando os mapas iniciais e finais, as participantes da pesquisa não utilizaram adequadamente de preposições válidas e em grande parte dos conceitos interligados houve ausência de relação entre eles. Desse modo, o menor quantitativo de palavras de ligação entre os conceitos revela uma maior preocupação dos estudantes em articular os conceitos sem necessariamente interligá-los, situação quase absoluta nos mapas finais. Se considerarmos a estratégia criteriosamente, segundo a descrição de Anastasiou e Alves (2005) e de Marriot e Torres (2007), quando ocorre ausência desses termos de ligação diz-se que a relação entre os conceitos não é válida, pois não tem clareza de relação. Em uma análise quantitativa poderíamos indicar efeitos negativos no aprendizado, pois evidencia que as alunas não foram claras quanto à relação entre os conceitos listados.

Destacamos ainda, no comparativo geral, um aumento no total de relações, o que sugere que as alunas adquiriram novos conceitos ao decorrer das aulas. O expressivo aumento na quantidade de relações evidencia que o mapa conceitual é uma estratégia potencialmente significativa, que contribui para que o aluno articule ou revise conceitos durante o processo de aprendizagem.

Num processo qualitativo de avaliação, em que pese o fato de ser possível que o professor saliente a importância das preposições válidas para auxiliar na construção do raciocínio, investigando a qualidade da aprendizagem é possível que eles auxiliem na avaliação formativa dessa. $\mathrm{E}$, ainda, os conhecimentos prévios podem ser expressos em mapas conceituais de representações mais simples, a fim de explicitar um diagnóstico da aprendizagem. Por isso, nos dedicamos a aprofundar as 
evidências qualitativas em detrimento de uma análise quantitativa (LUCKESI, $2011 \mathrm{~b}$; VEIGA, 2013).

Em síntese, por um lado os mapas iniciais contribuíram para diagnosticar os conhecimentos prévios das alunas, permitindo que determinados conteúdos fossem trabalhados com mais enfoque que outros, como, as glândulas anexas que não foram citadas nos mapas iniciais, o que corrobora com a compreensão que os mapas são capazes de mostrar as fragilidades na aprendizagem (VEIGA, 2013; MENDONÇA; SILVEIRA; MOREIRA, 2011).

Por outro lado, os mapas finais evidenciaram um aumento de conceitos a respeito do tema e um aumento de operações de pensamento utilizadas pelas alunas durante a sua construção. Isso demonstra que o mapa se trata de uma ferramenta que permite avaliar o aprendizado, além de investigar o conhecimento. A avaliação pode ser feita de várias maneiras diferentes, para além das sugeridas por Anastasiou e Alves (2005), a fim de obter informações da estrutura cognitiva e salientar a (re)estruturação dos conceitos por meio de conflitos cognitivos (VEIGA, 2013; SOUZA; PINHEIRO; MIQUELIN, 2018; VIEIRA; CASTAMAN; INOCENTE, 2018).

\section{CONSIDERAÇÕES FINAIS}

O delineamento teórico fundante do estudo indicou que o mapa conceitual pode ser uma estratégia potencialmente significativa quando pautado em um processo de ensino-aprendizagem que permita a observação do desenvolvimento da aprendizagem, o que indica a necessidade de: conhecimento da estratégia a ser utilizada, desenvolvimento de um repertório de operações de pensamento, a avaliação como um processo qualitativo para a aprendizagem. Porém, nesse processo pudemos observar que ainda carecem de estudos no ensino de ciências utilizando os mapas conceituais.

Metodologicamente, apenas um estudo foi realizado na área de Ciências com o ensino fundamental. Esse, assim como na pesquisa desenvolvida, evidencia um processo de aprendizagem, o qual é gradual e 
necessita do constante feedback e orientação do professor para que essa possua potencial significativo.

Quanto ao problema de pesquisa ao qual nos debruçamos investigar, consideramos que o desenvolvimento do mapa conceitual em dois momentos do processo de ensino-aprendizagem oportunizou:

- $\quad$ evidenciar os subsunçores que as alunas já possuíam, bem como as fragilidades da aprendizagem;

- expressar a rede de relações que essas construíram entre os conhecimentos prévios e assimilados;

- demonstrar as operações de pensamento utilizadas durante o processo de construção do mapa conceitual;

- exibir a variedade de representação do conhecimento que pode ocorrer na utilização desta ferramenta;

- destacar o papel do professor como mediador do processo para que os alunos não apenas se preocupem em elaborar o mapa conceitual para demonstrar sua aprendizagem, mas compor preposições válidas entre os conceitos para que, posteriormente, ele possa ser utilizado para eventuais retomadas e revisões;

- o mapa conceitual constitui a essência do processo didático, ao que permite ações de ensino, aprendizagem, pesquisa e avaliação de modos plurais e entre os sujeitos envolvidos no ensino, não apenas do professor para o aluno.

No ensino de Ciências, o mapa conceitual possibilitou evidenciar o aumento de conceitos e de relações entre esses a respeito do sistema digestório nos mapas finais, mostrou o aumento das operações de pensamento utilizadas pelas alunas, algumas exigindo um complexo processo de pensamento, além de expor as particularidades do aprendizado de cada aluna.

Desse modo, a pesquisa realizada evidencia que o mapa conceitual é uma estratégia potencialmente significativa, desde que não seja objeto apenas de uma avaliação somativa, mas para análise do processo de aprendizagem na qual seja possível investigar a construção do 
conhecimento e observar a ressignificação de ideais que ocorrem na estrutura cognitiva do aluno.

\section{REFERÊNCIAS}

ANASTASIOU, L. G. C.; ALVES, L. P. Estratégias de ensinagem. In: ANASTASIOU, L. G. C.; ALVES, L. P. (org.). Processos de ensinagem na Universidade: pressupostos para as estratégias de trabalho em aula. $5^{a}$ ed. Joinville: Univille, 2005.

ANDRADE, R. D. F. Processo de significação dos conceitos de ciências da natureza no contexto de situação de estudo. 2016. 134 f. Dissertação (Mestrado em Educação nas Ciências) - Universidade Regional do Noroeste do Estado do Rio Grande do Sul, ljuí, 2016.

ARELLANO, J.; SANTOYO, M. Investigar com mapa conceptuales: Processo metodológicos. De ediciones: Madrid, 2009.

BORSSOI, A. H.; ALMEIDA, L. M. W. Uma aproximação entre modelagem matemática e unidade de ensino potencialmente significativas para a aprendizagem significativa: o caso das equações de diferenças.

Investigação no ensino de ciências, Londrina, v. 18, n. 2, p. 481-503, 2013.

CATANI, D. B.; GALLEGO, R. C. Avaliação. São Paulo: Editora UNESP, 2009.

DEPRESBITERIS, L.; TAVARES, M. R. Diversificar é preciso: instrumentos e técnicas de avaliação da aprendizagem. São Paulo: Editora Senac, 2009.

FORTE, V. H. Mapas conceptuales: La gestión del conocimiento em la didáctica. $2^{a}$ ed. México: Alfaomega. 2007.

LOURENÇO, A. B. Análise de mapas conceituais elaborados por alunos da oitava série do ensino fundamental a partir de aulas pautadas na teoria da Aprendizagem Significativa: a argila como tema de estudo. 2008. $155 \mathrm{f}$. Dissertação (Mestrado em Educação) - Universidade Federal de São Carlos, São Carlos, 2008.

LUCKESI, C. C. Avaliação da aprendizagem: componente do ato pedagógico. São Paulo: Cortez, 2011 b.

LUCKESI, C. C. Avaliação Educacional Escolar: para além do autoritarismo. In: LUCKESI, C. C. Avaliação da Aprendizagem Escolar: estudos e proposições. $22^{a}$ ed. São Paulo: Cortez, 201 1a. p. 75-93.

MAGALHÃES, M. A. D. Mapas conceituais: uma proposta para o estímulo à aprendizagem de física no Ensino Fundamental II. 2015, 82 f. Dissertação 
(Mestrado em Ensino de Biologia) - Pontifícia Universidade Católica de Minas Gerais, Belo Horizonte, 2015.

MARRIOTT, R. C. V.; TORRES, P. L. Mapas conceituais. In: TORRES, Patricia Lupion (org.). Algumas vias para entretecer o pensar e o agir. Curitiba: SenarPR, 2007. p. 150-190.

MENDONÇA, C. A. S.; SILVEIRA, F. P. R. A.; MOREIRA, M. A. Mapa conceitual: um recurso didático para o ensino dos conceitos sobre Sistema Respiratório. In: Encontro Nacional de Pesquisa em Educação em Ciências, 8, 2011, Campinas. Anais[...]. Campinas, São Paulo, 2011. Disponível em: <http://www.nutes.ufrj.br/abrapec/viiienpec/resumos/R1 195-1.pdf>. Acesso em: 24 mar 2020.

MOREIRA, M. A. Al final, qué es aprendizaje significativo? Revista Qurriculum, La Laguna, n. 25, p. 29-56, 2012.

MOREIRA, M. A. Aprendizagem significativa em mapas conceituais. Textos de Apoio ao Professor de Física, Porto Alegre, v. 24, n. 6, p. 2-55, 2013.

MOREIRA, M. A. Mapas conceituais e aprendizagem significativa. Cadernos da aplicação, Porto Alegre, n. 11, p. 143-156, 1998.

NADAL, B. G.; LEÃO, T. J. E. Avaliação do ensino e da aprendizagem. Olhar de professor, Ponta Grossa, v. 5, n. 1, p. 119-127, 2002.

NOVAK, J. D.; CAÑAS, A. J. A teoria subjacente aos mapas conceituais e como elaborá-los e usá-los. Práxis Educativa, Ponta Grossa, v. 5, n. 1, p. 9-29, 2010.

OLIVEIRA, A. M.; HENCKES, S. B. R.; STROHSCHOEN, A. A. G. Mapa conceitual e World Café: ressignificando o ensino de ciências pela argumentação.

Research, Society and Development, Taquari, v. 8, n. 3, 2019.

RATHS, L. E. et al. Ensinar a pensar: teoria e aplicação. São Paulo: EPU, 1977.

SALVIATO, G. M. S. Multimodos de representação e a aprendizagem significativa de estudantes do ensino fundamental sobre aquecimento global: uma estratégia didática. 2009, 107 f. Dissertação (Mestrado em Ensino de Ciências e Educação Matemática) - Universidade Estadual de Londrina, Londrina, 2009.

SANTOS, J.; MEIRA, K. C. Operações de pensamento e estratégias de ensino: relações e complexidade como uma alternativa para tomada de decisão na dinâmica dos processos de ensino-aprendizagem. Revista Eletrônica Gestão \& Saúde, [s. I.], v. 6, n. 3, p. 2024-38, abr. 2015. 
SOUZA, G. F.; PINHEIRO, N. A. M.; MIQUELIN, A. F. Mapas conceituais no ensino de ciências: uma proposta para a aprendizagem significativa de conceitos científicos nos anos iniciais. Revista Educere Et Educare, [s. I.], v. 13, n. 30, nov/dez 2018.

SOUZA, N. A.; BORUCHOVITCH, E. Mapas conceituais e avaliação formativa: tecendo aproximações. Educação e Pesquisa, São Paulo, v. 36, n. 3, p. 795810, set/dez 2010.

TAVARES, R. Construindo mapas conceituais. Ciências \& Cognição. [s. l.], v. 12, p. 72-85, 2007.

THIOLLENT, M. Metodologia da pesquisa-ação. São Paulo: Cortez, 1996.

VEIGA, I. P. A. Novas tramas para as técnicas de ensino e estudo. Campinas: Papirus, 2013.

VIEIRA, M. L.; CASTAMAN, A. S.; INOCENTE, L. Mapa conceitual: instrumento de avaliação educacional no curso de Agronomia. Unoesc \& Ciência ACHS, Joaçaba, v. 9, n. 1, p. 57-64, 2018.

WEBER, M. M. Aulas práticas no ensino de ciências: a construção do conhecimento científico sobre protozoários por alunos do $7^{\circ}$ ano do ensino fundamental. 2013. 90 f. Dissertação (Mestrado em Educação para a Ciência e a Matemática) - Universidade Estadual de Maringá, Maringá, 2013.

Recebido em: 12 de maio de 2020 Aprovado em: 15 de setembro de 2020 Publicado em: 17 de novembro de 2020 